\title{
Aminolysis of 2,4-Dinitrophenyl and 3,4-Dinitrophenyl Benzoates: Effect of ortho-Nitro Group on Reactivity and Mechanism
}

\author{
Jin-A Seo, Hye-Min Lee, and Ik-Hwan Um* \\ Department of Chemistry and Nano Science, Euha Womans University, Seoul 120-750, Korea. E-mail: ihum@enha.ac.k \\ Received July: 31,2008
}

\begin{abstract}
Second-order rate constants $\left(k_{\mathrm{N}}\right)$ have been measured spectrophotometrically for reactions of 3,4-dinitrophenyl benzoates (5b) with a series of alicyclic secondary amines in $80 \mathrm{~mol} \% \mathrm{H}_{2} \mathrm{O} / 20 \mathrm{~mol} \%$ DMSO at $25.0 \pm 0.1{ }^{\circ} \mathrm{C}$. The kinetic data have been compared with the data reported previously for the corresponding reactions of 2,4dinitrophenyl benzoates (5a) to investigate the effect of changing the moleofuge from 2,4-dinitrophenoxide to 3,4-dinitrophenoxide on reactivity and mechanism. The kinetic results show that aminolyses of $\mathbf{5 a}$ and $\mathbf{5 b}$ proceed through the same mechanism, i.e., a zwitterionic tetrahedral intemediate $\left(\mathrm{T}^{ \pm}\right)$witl a change in the rate-determining step (RDS). Substrate $\mathbf{5} \mathbf{a}$ is more reactive than $\mathbf{5 b}$ when breakdown of $\mathrm{T}^{ \pm}$is the RDS but less reactive when formation of $\mathrm{T}^{ \pm}$is the RDS. Dissection of $k_{N}$ values into the microscopic rate constants (e.g., $k_{1}$ and $k_{2} / k_{\text {] }}$ ratio) has revealed that $5 \mathbf{a}$ results in larger $k_{2} / k_{-1}$ ratios but smaller $k_{1}$ values than $\mathbf{5} \mathbf{b}$ for all the amines studied. Since 2,4-dinitrophenoxide is less basic and a better nucleofuge than 3,4-dinitrophenoxide, the larger $k_{2} / k_{-1}$ ratios determined for the reactions of $\mathbf{5} \mathbf{a}$ than for those of $\mathbf{5 b}$ are as expected. The steric hindrance exerted by the ortho-nitro group on $\mathbf{5 a}$ contributes to the smaller $k_{1}$ values found for the reactions of $\mathbf{5 a}$ than for those of $\mathbf{5 b}$.
\end{abstract}

Key Words : Aminolysis, Bronsted-type plot, Steric hindrance, Reaction mechanisn, ontho-Effect

\section{Introduction}

Aminolysis of esters has generally been understood to proceed through a stepwise mechanism with a zwitterionic tetrahedral intermediate, $T^{=1.7}$ Curved Brønsted-type plots have often been reported for reactions of esters which possess a good leaving group ( $e . g$, from a large $\beta_{\text {ulk }}$ to a small one as the attacking amine becomes more basic than the leaving group by 4 to $5 \mathrm{p} K_{\text {it }}$ units). Such a curved Brønsted-type plot has often been suggested as evidence for a change in rate-determining step (RDS) of a stepwise mechanism. ${ }^{1-7}$

Brønsted and Hammett equations have most commonly been employed to investigate reaction mechanism and/or to correlate reactivity with basicity or substituent constants. ${ }^{8}$ It is well known that nucleophilicity increases with increasing the basicity of nucleophiles while nucleofugality decreases with increasing the basicity of nucleofiges. However, Gresser and Jencks found that 2,4-dinitrophenyl phenyl carbonate is less reactive than 3,4-dinitrophenyl phenyl carbonate toward quinuclidines, ${ }^{\text {id }}$ although 2,4-dinitrophenoxide is less basic than 3,4-dinitrophenoxide by $c a .1 .3 \mathrm{p} K_{\mathrm{a}}$ units. Gresser and Jencks concluded that steric hindrance is responsible for the decreased reactivity of 2,4-dinitrophenyl phenyl carbonate compared to 3,4-dinitrophenyl phenyl carbonate, since the nitro group at the ortho-position may cause steric hindrance.

A similar result has been reported for aminolysis of 2,4dinitrophenyl and 3,4-dinitrophenyl 2-furoates (1a and 1b) and 2-thiophenecarboxylates (2a and $\mathbf{2 b}$ ). ${ }^{9}$ We found that $\mathbf{1 a}$ is only slightly more reactive than $\mathbf{1 b}$ toward piperidine, ${ }^{9 a}$ while $\mathbf{2 a}$ is even less reactive than $\mathbf{2} \mathbf{b} .{ }^{90}$ Dissection of the macroscopic second-order rate constant $\left(k_{\mathrm{N}}\right)$ into the microscopic rate constants $\left(e, g, k_{1}\right.$ and $\left.k_{2} / k_{-1}\right)$ has shown that 1 a and 2a exhibit smaller $k_{1}$ values but larger $k_{2} / k_{-1}$ ratios than $\mathbf{1 b}$ and $2 \mathrm{~b}$, respectively." Our studies on the aminolyses of 1a, $\mathbf{b}$ and $2 \mathbf{a}, \mathbf{b}$ have shown that steric hindrance contributes to the smaller $k_{1}$ values for the reactions of the substrates with an ortho-nitro group (e.g., $1 \mathbf{a}$ and $\mathbf{2 a}$ ).

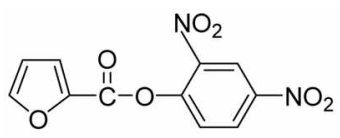

$1 a$

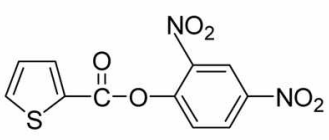

$2 a$

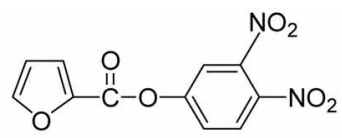

$1 \mathrm{~b}$

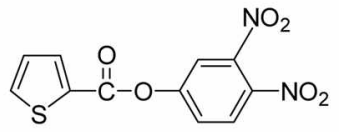

$2 b$
However, we have found that the steric hindrance reported for the reactions of the carbonyl esters ( $\mathbf{1 a}$ and $\mathbf{2 a}$ ) is absent for aminolyses of phosphorus centered esters, since 2,4-

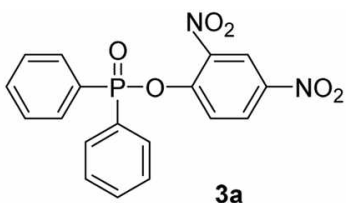

3a

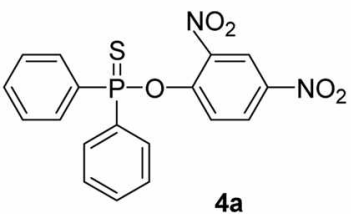

$4 a$

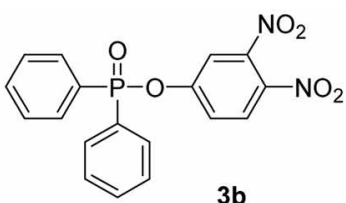

$3 b$

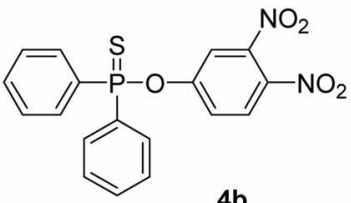



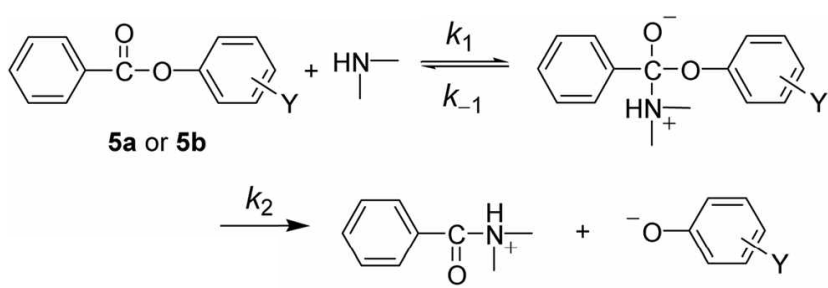

$Y=2,4-\left(\mathrm{NO}_{2}\right)_{2}(5 \mathbf{a}): Y=3,4-\left(\mathrm{NO}_{2}\right)_{2}(\mathbf{b} \mathbf{b})$

$\mathrm{HN}-=\mathrm{HN} Z \mathrm{R}=\mathrm{H}$ or $\mathrm{CH}_{3} ; \mathrm{Z}=\mathrm{CH}_{2}, \mathrm{NH}, \mathrm{CH}_{2} \mathrm{CH}_{2} \mathrm{OH}, \mathrm{O}, \mathrm{NCHO}, \mathrm{NH}_{2}^{+}$

Scheme 1

dinitrophenyl diphenylphosphinate (3a) and diphenylphosphinothioate (4a) are more reactive than 3.4-dinitrophenyl diphenylphosphinate (3b) and diphenylphosphinothioate (4b), respectively. ${ }^{\text {latb }}$ Furthermore, the Brønsted-type plots have been found to be linear for aminolyses of Y-substituted phenyl diphenylphosphinates and diphenylphosphinothioates including $3 \mathbf{a}$ and $4 \mathbf{a}^{10 \mathrm{ab}}$

We performed a kinetic study on aminolysis of 2,4 dinitrophenyl benzoate ( $5 \mathrm{a}$ ) and concluded that the reaction proceeds through $\mathrm{T}^{*}$ with a change in the RDS on the basis of a curved Brensted-type plot. ${ }^{7 \mathrm{a}, \mathrm{l}}$ The kinetic study has now been extended to reactions of 3.4-dinitrophenyl benzoate (5b) with a series of alicyclic secondary amines (Scheme 1). The kinetic data in the current study have been compared with those reported previously for the corresponding reactions of $5 \mathbf{a}$ to investigate the effect of changing the nucleofuge from 2,4-dinitrophenoxide to 3,4-dinitrophenoxide on the reactivity and reaction mechanism (i.e., an orthosubstituent effect) in a microscopic rate constant level.

\section{Results and Discussion}

The reactions of $\mathbf{5} \mathbf{b}$ with all the amines studied in this work obeyed first-order kinetics and proceeded with quantitative liberation of 3,4-dinitrophenoxide ion under pseudofirst-order conditions. Pseudo-first-order rate constants $\left(k_{w b s i t}\right)$ were determined from the equation, $\ln \left(A-A_{l}\right)=-k_{\text {wbsid }} t+C$. The plots of $k_{\text {wbsid }}$ is. the amine concentration were linear passing through the origin, indicating that general base catalysis by a second amine molecule is absent and the contribution of $\mathrm{H}_{2} \mathrm{O}$ and/or $\mathrm{OH}^{-}$ion from the hydrolysis of amines to $k_{0 b s i d}$ is negligible. Accordingly, the rate equation can be given as eq (1). The second-order rate constants $\left(k_{\mathrm{N}}\right)$ were determined from the slope of the linear plots of $k_{\text {wbst }} v s$. the amine concentration. Five different amine concentrations were used to determine $k_{\mathrm{N}}$ values. It is estimated from replicate runs that the uncertainty in the rate constants is less than $3 \%$. The $k_{\mathrm{v}}$ values determined in this way are summarized in Table 1.

$$
\text { rate }=k_{0 \mathrm{bsd}}[5 \mathrm{~b}] \text {, where } k_{0 \mathrm{bsd}}=k_{\mathrm{N}}[\mathrm{amine}]
$$

Effect of ortho-Nitro Group on Reactivity and Mechanism. Table 1 shows that the second-order rate constant $\left(k_{\mathrm{N}}\right)$
Table 1. Summary of Second-order Rate Constants $\left(k, \mathrm{M}^{-1} \mathrm{~s}^{-1}\right)$ for Reactions of 2,4-Dinitrophenyl Benzoate (5a) and 3.4-Dinitrophenyl Benzoate (5b) with Secondary Alicyclic Amines in $20 \mathrm{~mol}$ $\%$ DMSO at $25.0 \pm 0.1^{\circ} \mathrm{C}^{a}$

\begin{tabular}{|c|c|c|c|c|}
\hline \multirow{2}{*}{ Entry } & \multirow{2}{*}{ Amines } & \multirow{2}{*}{$\mathrm{p} K_{:}^{\prime}$} & \multicolumn{2}{|c|}{$k=\mathrm{M}^{-1} \mathrm{~s}^{-1}$} \\
\hline & & & $5 a$ & 5b \\
\hline 1 & piperidine & 11.02 & 174 & 191 \\
\hline 2 & 3-methylpiperidine & 10.80 & 167 & 182 \\
\hline 3 & piperazine & 9.85 & 82.1 & 61.7 \\
\hline 4 & morpholine & 8.65 & 19.6 & 10.0 \\
\hline 5 & 1-fomylpiperazine & 7.98 & 5.43 & 2.66 \\
\hline 6 & piperazinium ion & 5.95 & 0.467 & 0.0867 \\
\hline
\end{tabular}

for the reaction of $\mathbf{5 b}$ decreases with decreasing the basicity of amines, i.e., $k_{\mathrm{N}}$ decreases from $191 \mathrm{M}^{-1} \mathrm{~s}^{-1}$ to 10.0 and $0.0867 \mathrm{M}^{-1} \mathrm{~s}^{-1}$ as the $\mathrm{p} K_{\mathrm{a}}$ of amines decreases from 11.02 to 8.65 and 5.95 , respectively. A similar result is presented for the corresponding reactions of $\mathbf{5 a}$. It is noted that $5 \mathrm{~b}$ is less reactive than 5a when the attacking amines are weakly basic (i.e., $\mathrm{p} K_{\mathrm{a}} \leq 9.85$ ) but becomes more reactive as the amine basicity increases further (i.e., $\mathrm{p} K_{\mathrm{a}} \geq 10.80$ ).

In Figure 1 is demonstrated the effect of amine basicity on reactivity as well as the effect of changing the nucleofuge from 2,4-dinitrophenoxide to 3,4-dinitrphenoxide. The Brensted-type plot for the reactions of $\mathbf{5 b}$ is curved downwardly, when $k_{\mathrm{N}}$ and $\mathrm{p} K_{\mathrm{a}}$ are statistically corrected using $p$ and $q$ (i.e., $p=2$ except $p=4$ for piperazinium ion and $q=1$ except $q=2$ for piperazine). ${ }^{11}$ A similar result is shown for the corresponding reactions of 5a. However, the slopes of the Brensted-type plots are slightly different, i.e., the slope decreases from 0.83 to 0.34 and from 0.74 to 0.34 as the

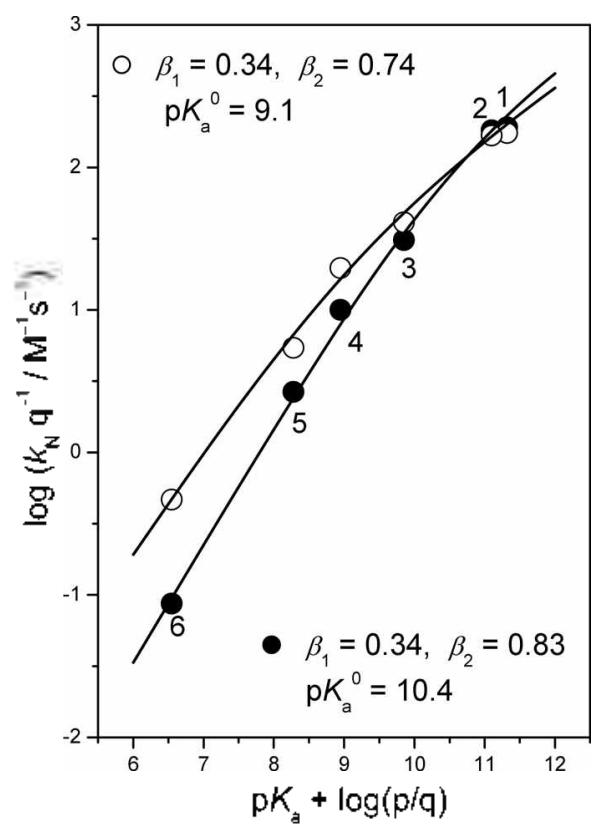

Figure 1. Bronsted-type plots for the reactions of $\mathbf{5 a}(C)$ and $\mathbf{5 b}$ (O) with secondary alicyclic amines in $80 \mathrm{~mol} \% \mathrm{H}_{2} \mathrm{O} / 20 \mathrm{~mol} \%$ DMSO at $25.0 \pm 0.1^{\circ} \mathrm{C}$. The identity of points is given in Table 1 . 
amine basicity increases for the reactions of $\mathbf{5 b}$ and $\mathbf{5 a}$. respectively. It is also noted that $\mathbf{5 a}$ is more reactive than $\mathbf{5 b}$ when the attacking amine is weakly basic but becomes slightly less reactive when the amine is strongly basic (e.g. $\mathrm{p} K_{\mathrm{a}} \geq 10.80$ ).

It is known that a change in RDS occurs at the center of the Bronsted curvature, defined as $\mathrm{p} K_{\mathrm{a}}{ }^{\mathrm{v}}{ }^{12}$ The $\mathrm{p} K_{\mathrm{a}}{ }^{0}$ for ester aminolysis has generally been reported to be 4 to $5 \mathrm{p} K_{a}$ units higher than the $\mathrm{p} K_{\mathrm{a}}$ of the conjugate acid of leaving group. .-4 $^{2-4}$ The center of the Bronsted curvature for the reactions of $\mathbf{5 a}$ was determined to be 9.1. which is $c a .5 \mathrm{p} K_{\mathrm{a}}$ units higher than the $\mathrm{p} K_{\mathrm{a}}$ of 2,4-dinitrophenol (i.e., $\mathrm{p} K_{\mathrm{a}}=4.11$ ), the conjugate acid of the leaving group. Thus, the curved Brønsted-type plot for the reactions of 5 a was interpreted as a change in the RDS. ${ }^{7}$ The center of the Brensted curvature for the reactions of $\mathbf{5 b}$ determined is 10.4 , which is also $c a .5$ $\mathrm{p} K_{\mathrm{a}}$ units higher than the $\mathrm{p} K_{\mathrm{a}}$ of 3.4-dinitrophenol (i.e., $\mathrm{p} K_{\mathrm{a}}=$ 5.42 ). Thus, one can suggest that the reactions of $5 \mathrm{~b}$ proceed also through a stepwise mechanism with a change in the RDS on the basis of the curved Brønsted-type plot.

To test whether the aminolyses of $\mathbf{5 a}$ and $\mathbf{5 b}$ proceed through the same mechanism or not, a plot of $\log k \mathrm{v}$ for the reactions of 5a $v$. log $k_{\mathrm{N}}$ for the corresponding reactions of 5 b has been constructed. As shown in Figure 2, an excellent linear correlation is obtained (i.e., $\mathrm{R}^{2}=0.9992$ ) with a slope of 1.29. Such a good linear plot suggests that the reactions of $5 \mathrm{a}$ and $\mathbf{5 b}$ proceed through the same mechanism. The fact that the slope is larger than unity implies that $\mathbf{5 b}$ is more sensitive than $\mathbf{5 a}$ toward amine basicity. Accordingly, one can conclude that modification of the nucleofuge from 2,4dinitrophenoxide to 3.4-dinitrophenoxide influences the reactivity but not the reaction mechanism.

Dissection of Macroscopic Rate Constants into Microscopic Rate Constants. On the basis of the mechanism

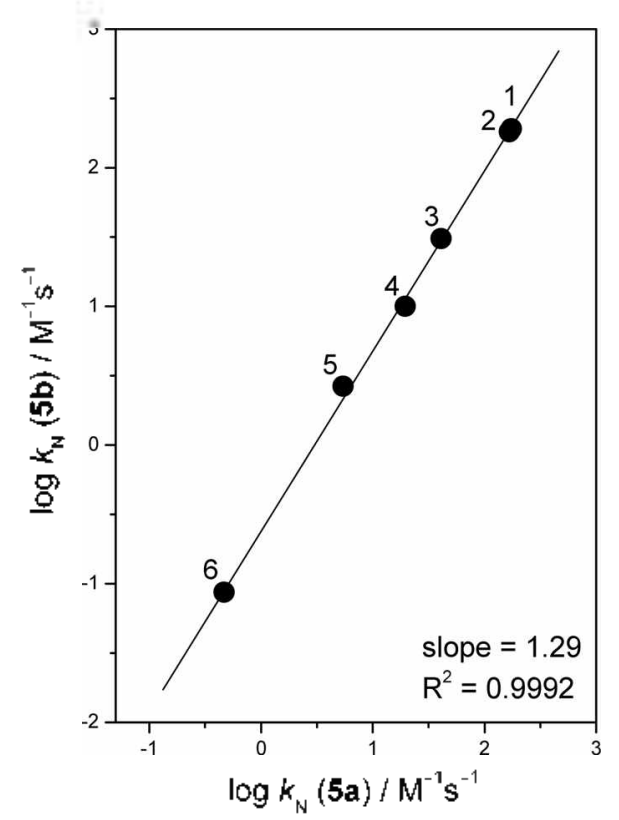

Figure 2. Plot of $\log k$. for the reactions of $5 \mathrm{a}$ us. $\log k$. for the reactions of $\mathbf{5 b}$ in $80 \mathrm{~mol} \% \mathrm{H}_{2} \mathrm{O} / 20 \mathrm{~mol} \%$ DMSO at $25.0 \pm 0.1$ ${ }^{10} \mathrm{C}$. The identity of points is given in Table 1 . proposed above, the curved Bronsted-type plot for the aminolysis of $\mathbf{5 b}$ has been analyzed using a semiempirical equation (eq. 2). ${ }^{\text {j,12 }}$ The parameters $\beta_{1}$ and $\beta_{2}$ represent the slope of the curved Bronsted plot for the reactions with strongly basic and weakly basic amines, respectively. Here $k_{\mathrm{N}}{ }^{\circ}$ refers to the $k_{\mathrm{v}}$ value at $\mathrm{p} K_{\mathrm{a}}^{\circ}$. The parameters determined from the fitting of eq. (2) to the experimental points are $\beta_{1}=$ $0.34, \beta_{2}=0.83$, and $\mathrm{p} K_{4}{ }^{\circ}=10.4$ for the reactions of $\mathbf{5 b}$.

$$
\begin{aligned}
& \log \left(k_{\mathrm{N}} / k_{\mathrm{N}}{ }^{\circ}\right)=\beta_{\mathrm{z}}\left(\mathrm{p} K_{\mathrm{a}}-\mathrm{p} K_{\mathrm{a}}{ }^{\circ}\right)-\log [(1+\alpha) / 2] \\
& \text { where } \log \alpha=\left(\beta_{2}-\beta_{1}\right)\left(\mathrm{p} K_{\mathrm{a}}-\mathrm{p} K_{\mathrm{a}}{ }^{\circ}\right)
\end{aligned}
$$

The $k_{\mathrm{N}}$ values for the reactions of $\mathbf{5 b}$ have been dissected into their microscopic rate constants through eqs. (3)-(10) as shown below. The macroscopic second-order rate constant $k_{\mathrm{N}}$ can be expressed as eq. (3) by applying the steady-state conditions to the intermediate on the basis of the proposed mechanism.

$$
k_{\mathrm{N}}=k_{1} k_{2} /\left(k_{-1}+k_{2}\right)
$$

The $k_{2} / k_{-1}$ ratios associated with the aminolysis of $\mathbf{5 b}$ have been determined using eqs. (4)-(9). Eq. (3) can be simplified to eq. (4) or (5). Then, $\beta_{1}$ and $\beta_{2}$ can be expressed as eqs. (6) and (7), respectively.

$$
\begin{aligned}
k_{\mathrm{N}} & =k_{1} k_{2} / k_{-1}, \text { when } k_{2}<k_{-1} \\
k_{\mathrm{N}} & =k_{1}, \text { when } k_{2}>>k_{-1} \\
\beta_{1} & =\mathrm{d}\left(\log k_{1} y / \mathrm{d}\left(\mathrm{p} K_{\mathrm{a}}\right)\right. \\
\beta_{\underline{1}} & =\mathrm{d}\left(\log k_{1} k_{2} / k_{-1}\right) / \mathrm{d}\left(\mathrm{p} K_{\mathrm{a}}\right) \\
& =\beta_{1}+\mathrm{d}\left(\log k_{2} / k_{-1}\right) / \mathrm{d}\left(\mathrm{p} K_{\mathrm{a}}\right)
\end{aligned}
$$

Eq. (7) can be rearranged as eq. (8). Integral of eq. (8) from $\mathrm{p} K_{\mathrm{a}}{ }_{\mathrm{o}}$ results in eq. (9). Since $k_{2}=k_{-1}$ at $\mathrm{p} K_{\mathrm{a}}{ }^{\mathrm{o}}$, the term $\left(\log k_{2} / k_{-1}\right)_{p \mathrm{Hi}^{\circ}}$ is zero. Therefore, one can calculate the $k_{2} / k_{-1}$ ratios for the aminolysis of $\mathbf{5 b}$ from eq. (9) using $\mathrm{p} K_{\mathrm{a}}{ }^{\mathrm{a}}=$ 10.4, $\beta_{1}=0.34$, and $\beta_{1}=0.83$. The $k_{1}$ values have been determined from eq. (10) using the $k_{\mathrm{N}}$ values in Table 1 and the $k_{2} / k_{-1}$ ratios calculated above. The $k_{2} / k_{-1}$ ratios and $k_{1}$ values are summarized in Table 2 together with the data for the corresponding reactions of $\mathbf{5 a}$.

$$
\begin{aligned}
& \beta_{2}-\beta_{1}=\mathrm{d}\left(\log k_{2} / k_{-1}\right) / \mathrm{d}\left(\mathrm{p} K_{\mathrm{a}}\right) \\
& \left(\log k_{\underline{2}} / k_{-1}\right)_{\mathrm{p} K \mathrm{u}}=\left(\beta_{\underline{1}}-\beta_{1}\right)\left(\mathrm{p} K_{\mathrm{u}}-\mathrm{p} K_{\mathrm{a}}{ }^{0}\right)
\end{aligned}
$$

Table 2. Summary of Microscopic Rate Constants $k y / k_{-1}$ Ratios and $k_{1}$ values for the Reactions of $\mathbf{5 b}$ and $\mathbf{5 a}$ (in parentheses) with Secondary Alicyclic Amines in $80 \mathrm{~mol} \% \mathrm{H}, \mathrm{O} / 20 \mathrm{~mol} \% \mathrm{DMSO}$ at $25.0 \pm 0.1^{\circ} \mathrm{C}^{\mathrm{tt}}$

\begin{tabular}{clrll}
\hline Entry & Amine & $\mathrm{p} K_{3}$ & \multicolumn{1}{c}{$k 2 / k_{+}$} & \multicolumn{1}{c}{$k_{1} / \mathrm{M}^{-1} \mathrm{~s}^{-1}$} \\
\hline 1 & piperidine & 11.02 & $2.82(7.73)$ & $258(197)$ \\
2 & 3-methylpiperidine & 10.80 & $2.20(6.31)$ & $265(193)$ \\
3 & piperazine & 9.85 & $0.538(2.00)$ & $176(123)$ \\
4 & morpholine & 8.65 & $0.195(0.871)$ & $61.3(42.1)$ \\
5 & 1-fomylpiperazine & 7.98 & $0.0915(0.470)$ & $31.7(17.0)$ \\
6 & piperazinium ion & 5.95 & $0.0130(0.096)$ & $6.76(5.36)$ \\
\hline
\end{tabular}

"The data in the parentheses for the reactions of $5 \mathbf{a}$ were taken from ref. $7 \mathbf{b}$. 


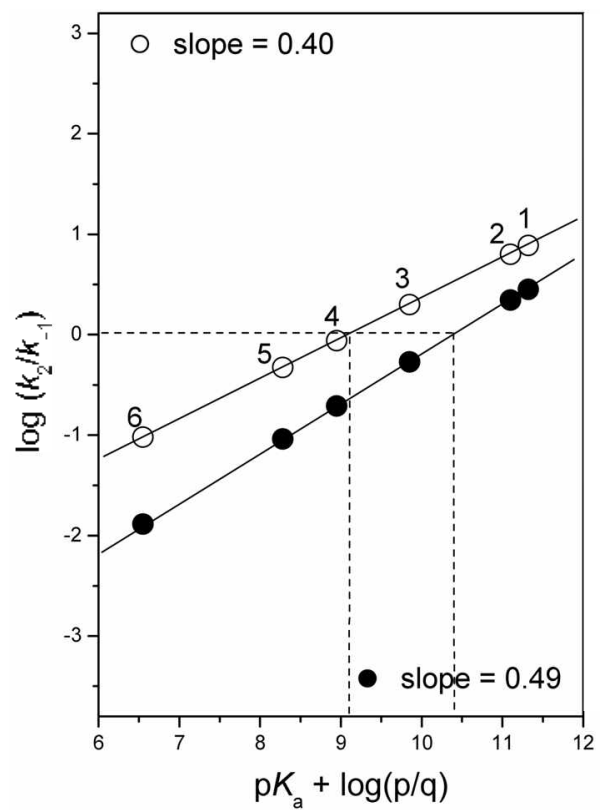

Figure 3. Plots of $\log k / k_{\text {, }}$ versus $\mathrm{p} K_{\text {a }}$ for the reactions of $\mathbf{5 a}(C)$ and 5 b (O) with secondary alicyclic amines in $80 \mathrm{~mol} \% \mathrm{H}_{2} \mathrm{O} / 20$ mol \% DMSO at $25.0 \pm 0.1^{\circ} \mathrm{C}$. The identity of points is given in Table 2

$$
k_{N}=k_{1} k_{2} /\left(k_{-1}+k_{2}\right)=k_{1} /\left(k_{-1} / k_{2}+1\right)
$$

Effect of ortho-Nitro Group on Microscopic Rate Constants. As shown in Table 2, the $k_{2} / k_{-1}$ ratio decreases as the amine basicity decreases. It is noted that $k_{2} / k_{-1}>1$ when $\mathrm{p} K_{\mathrm{a}}$ $\geq 10.80$ but $k_{2} / k_{-1}<1$ when $\mathrm{p}_{\mathrm{a}} \leq 9.85$ for the reactions of 5 b. On the other hand, $k_{2} / k_{-1}>1$ when $\mathrm{p} K_{\mathrm{a}} \geq 9.85$ but $k_{2} / k_{-1}$ $<1$ when $\mathrm{p} K_{\mathrm{a}} \leq 8.65$ for the reactions of $5 \mathrm{a}$. This is in accord with the proposal that the RDS for the aminolysis of $\mathbf{5 a}$ and $5 \mathrm{~b}$ changes at $\mathrm{p} K_{\mathrm{a}}=9.1$ and 10.4 , respectively.

The effect of amine basicity on the $k_{2} / k_{-1}$ ratio is illustrated in Figure 3. The plots are linear with slopes of 0.40 and 0.49 for the reactions of $\mathbf{5} \mathbf{a}$ and $\mathbf{5} \mathbf{b}$, respectively. The $k_{2}$ value has been suggested to be independent of amine basicity, since the push by the $\mathrm{N}$ atom of the aminium moiety of $\mathrm{T}^{ \pm}$to expel the leaving group is absent. ${ }^{\text {ld }}$ On the other hand, $k_{-1}$ would decrease with increasing amine basicity. This idea is consistent with the positive slope shown in Figure 3.

It is noted that 5 a exhibits a larger $k_{2} / k_{-1}$ ratio than 5 b for a given amine. Since 2,4-dinitrophenoxide is less basic and a better nucleofige than 3,4-dinitrophenoxide, one can expect 5a would exhibit a larger $k_{2}$ value than $\mathbf{5 b}$. In contrast, the leaving group basicity would not influence the $k_{-1}$ value significantly. Therefore, the fact that 5 a results in a larger $k_{2}$ i $k_{-1}$ ratio than $5 \mathrm{~b}$ is consistent with the expectation on the basis of the basicity of the leaving groups.

In Figure 4 are demonstrated Bronsted-type plots for $k_{1}$ for the reactions of $\mathbf{5 a}$ and $\mathbf{5 b}$. The plots are linear with similar slopes, i.e., $\beta_{1}=0.33$ and 0.34 for the reactions of $5 \mathrm{a}$ and $5 \mathrm{~b}$. respectively. Interestingly, $\mathbf{5 b}$ exhibits slightly larger $k_{1}$ values than $\mathbf{5 a}$ for all the amines studied. This is an unexpected result, since the $\mathrm{C}=\mathrm{O}$ bond of $5 \mathrm{~b}$ would be less electrophilic than that of $5 \mathbf{a}$ on the basis of the fact that 3,4-dinitro-

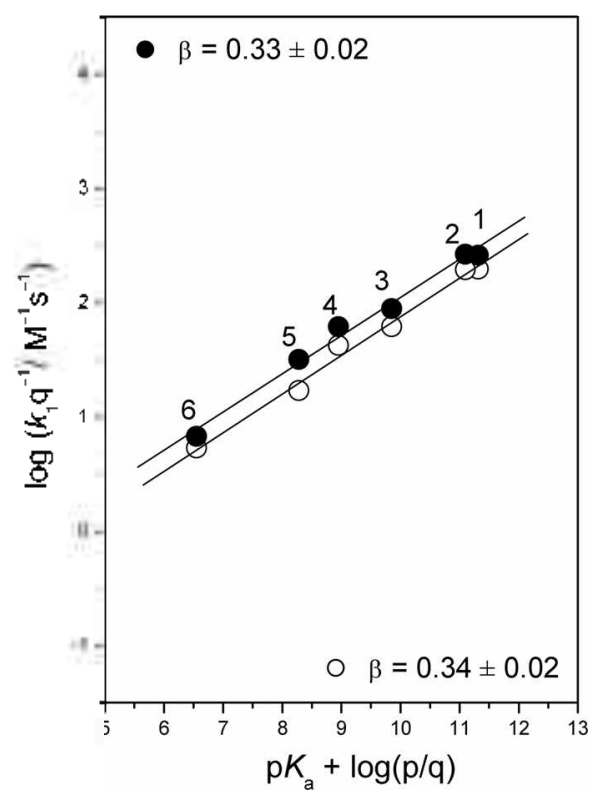

Figure 4. Bronsted-type plots for $k_{1}$ for the reactions of $5 \mathrm{a}(\mathrm{O})$ and $\mathbf{5 b}$ (1) with secondary alicyclic amines in $80 \mathrm{~mol} \% \mathrm{H}_{2} \mathrm{O} / 20$ mol \% DMSO at $25.0 \pm 0.1{ }^{\circ} \mathrm{C}$. The identity of points is given in Table 2 .

phenoxide is more basic than 2,4-dinitrophenoxide. Accordingly, the basicity difference between the two leaving groups cannot account for the difference in $k_{1}$ values determined for the aminolyses of $\mathbf{5 a}$ and $\mathbf{5 b}$

The ortho- $\mathrm{NO}_{2}$ in the nucleofuge of 5 a would exert steric hindrance when the amine approaches to the electrophilic center to form an intermediate, $\mathrm{T}^{ \pm}$(i.e., the $k_{1}$ step). Thus, one can suggest that steric hindrance exerted by ortho- $\mathrm{NO}_{2}$ is responsible for the fact that $\mathbf{5 a}$ results in smaller $k_{1}$ values than $5 \mathrm{~b}$.

However, the steric hindrance exerted by ortho- $\mathrm{NO}_{2}$ is insignificant when the $k_{2}$ step is RDS. This is because 5a results in larger $k_{\mathrm{N}}$ values than $\mathbf{5 b}$ when the $k_{1}$ step is the RDS (i.e., $\mathrm{p} K_{\mathrm{a}}<10.4$ ) but smaller $k_{\mathrm{v}}$ values when the $k_{\text {l }}$ step is the $\operatorname{RDS}$ (i.e, $\mathrm{p} K_{\text {u }}>10.4$ ). This argument can be further supported by the fact that $k_{\mathrm{N}}=k_{1} k_{2} / k_{-1}$ when the $k_{2}$ step is the RDS and the $k_{2} / k_{-1}$ ratios have been shown to be larger for the reactions of $\mathbf{5 a}$ than those of $\mathbf{5 b}$ (see Table 2 and Figure 3 ).

\section{Conclusions}

The current study has allowed us to conclude the following: (1) Modification of nucleofuge from 2,4-dinitrophenoxide to 3,4-dinitrophenoxide influences reactivity but does not affect mechanism for the aminolyses of $\mathbf{5 a}$ and $\mathbf{5 b}$. (2) Substrate $\mathbf{5 a}$ is more reactive than $\mathbf{5} \mathbf{b}$ when the $k_{2}$ step is the RDS but less reactive when the $k_{1}$ step is the RDS. (3) Steric hindrance exerted by the ortho-nitro group is responsible for the fact that $k_{1}$ is smaller for the reactions of $\mathbf{5 a}$ than for those of $\mathbf{5 b}$. (4) Substrate $\mathbf{5 a}$ exhibits larger $k_{2} / k_{-1}$ ratios th-an 5 b as expected from the fact that 2,4dinitrophenoxide is less basic and a better nucleofuge than 3,4-dinitrophenoxide. 


\section{Experimental Section}

Materials. Substrate 5b was readily prepared from the reaction of 3.4-dinitrophenol and benzoyl chloride in the presence of triethylamine in anhydrous ether and purified by column chromatography: $m p=110-111^{\circ} \mathrm{C} ;{ }^{l} \mathrm{H}$ NMR $(250$ $\left.\mathrm{MHz}, \mathrm{CDCl}_{3}\right) \delta 7.54-7.60(\mathrm{t}, J=7.5 \mathrm{~Hz}, 2 \mathrm{H}), 7.65-7.69$ (dd, $\left.J_{1}=10.0 \mathrm{~Hz}, J_{2}=2.5 \mathrm{~Hz}, 1 \mathrm{H}\right), 7.76-7.70(\mathrm{t}, J=7.5 \mathrm{~Hz}, 1 \mathrm{H})$, $7.85-7.86(\mathrm{~d}, J=2.5 \mathrm{~Hz}, 1 \mathrm{H}), 8.06-8.10(\mathrm{~d}, J=10.0 \mathrm{~Hz}, 1 \mathrm{H})$, 8.18-8.21 (d, $J=7.5 \mathrm{~Hz}, 2 \mathrm{H}$ ). Anal. Calcd for $\mathrm{C}_{13} \mathrm{H}_{8} \mathrm{~N}_{2} \mathrm{O}_{6}$; C. 54.17 ; H, 2.80. Found: C, 54.08; H, 2.82. Other chemicals including amines were of the highest quality available. Doubly glass distilled water was further boiled and cooled under nitrogen just before use.

Kinetics. Due to the low solubility of $\mathbf{5 b}$ in pure $\mathrm{H}_{2} \mathrm{O}, 20$ mol \% DMSO/80 mol $\% \mathrm{H}_{2} \mathrm{O}$ was used as the reaction medium for the kinetic study. The kinetic studies were performed with a Scinco S-3100 UV-Vis spectrophotometer equipped with a constant temperature circulating bath at $25.0 \pm 0.1^{\circ} \mathrm{C}$ for slow reactions (e.g., $t_{1: 2}>10 \mathrm{~s}$ ) or with an Applied Photophysics Stopped-flow spectrophotometer for fast reactions (e.g, $f_{1: 2}<10 \mathrm{~s}$ ). The reactions were performed under pseudo-first-order conditions, i.e., the amine concentration was at least 20 times greater than that of the substrate $5 \mathrm{~b}$ and followed by monitoring the appearance of the leaving 3,4-dinitrophenoxide ion at $410 \mathrm{~nm}$.

Products Analysis. 3,4-Dinitrophenoxide ion was liberated quantitatively and identified as one of the reaction products by comparison of the UV-vis spectra after the completion of the reactions with those of the authentic samples under the same reaction conditions.

Acknowledgments. This work was supported by a grant from Korea Research Foundation (KRF-2005-015-C00256). Jin-A Seo is also grateful for the BK 21 Scholarship.

\section{References}

1. (a) Jencks, W. P. Catalysis in Chemistra and Enzmologn; McGrawHill: New York, 1969 , pp 480-483. (b) Jencks, W. P. J. Chem. Soc. Rev 1981, $10,345-375$. (c) Jencks, W. P; Gilchrist, M. $J$. Am. Chem. Soc. 1968, 90, 2622-2637. (d) Gresser, M. J.; Jencks, W. P. J. Ant Chent Soc 1977, 99,6963-6970. (e) Williams, A. Ach: Phus Org. Chent 1992, 27, 2-55. (f) Menger, F. M.; Smith, I. H. J. Am. Chem. Soc. 1972, 94, 3824-3829.

2. (a) Castro, E. A.; Aliaga, M.; Santos, J. G. J. Ph: Org Chem.
2008, 21, 271-278. (b) Castro, E. A.; Aliaga, M.; Campodonico, P. R.; Leis, J. R.; Garcia-Rio, L.; Santos, J. G. J. Phn: Org. Chem. 2008, 21, 102-107. (c) Castro, E. A.; Echevarria, G R.; Opazo, A.; Robert, P. S.; Santos, J. G. J. Phi: Org. Chem. 2008, 21, 62-67. (d) Castro, E. A.: Echevarria, G. R.: Opazo, A.; Robert, P.: Santos, J. G J. Phis. Org. Chem. 2006, 19, 129-135. (e) Castro, E. A.; Campodonico, P. R.; Contreras, R.; Fuentealba, P.; Santos, J. G; Leis, J. R.; Garcia-Rio, L.; Saez, I. A.; Domingo, L. R. Tetrohedron 2006, 62, 2555-2562. (f) Castro, E. A.; Aliaga, M.; Gazitua, M.; Santos, J. G. Tetrahedron 2006, 62, 4863-4869. (g) Castro, E. A.; Aguayo, R.; Bessolo, J.; Santos, J. G J. Org. Chem. 2005, 70, 7788-7791. (h) Castro, E. A.; Aliaga, M.; Santos, J. G $J$. Org. Chem. 2005, 70, 2679-2685.

3. (a) Sung, D. D.; Kang, S. S.; Lee, J. P.; Jung, D. I.; Ryu, Z. H.; Lee, I. Bull. Korean Chem. Soc, 2007, 28,16701674 . (b) Hoque, M. E. L.; Dey, N. K.; Guha, A. K.; Kim, C. K.; Lee, B. S.; Lee, H. W. Bull. Korean Chem. Soc. 2007, 28, 1797-1802. (c) Kim, C. K.; Kim, D. J.; Zhang, H.; Hsieh, Y. H.; Lee, B. S.; Lee, H. W.; Kim, C. K. Bull. Korean Chem. Soc. 2007, 28, 1031-1034. (d) Ehtesham, M. H. U.; Lee, H. W. Bull. Korewn Chem. Soc. 2007, 28, 936-940. (e) Sung, D. D.; Koo, I. S.; Yang, K. Y.; Lee, I. Chen. Phns. Lett. 2006, 432, 426-430.

4. (a) Lm, 1. H.; Lee, J. Y.; Ko, S. H.; Bre, S. K. J. Org. Chem. 2006, $71,5800-5803$. (b) Lm, I. H.; Hwang, S. J.; Baek, M. H.; Park, E. J. J. Org. Chen. 2006, 7], 9191-9197. (c) Lin, I. H.; Kim, E. Y; Park, H. R. J. Org. Chem. 2006, 7l, 2302-2306. (d) Lm, I. H.; Lee, J. Y.; Fujio, M.; Tsuno, Y. Org. Bionol. Chem. 2006, 4, 29792985. (e) Lm, 1. H.; Lee, J. Y.; Lee, H. W.; Nagano, Y.; Fujio, M.; Tsuno, Y. J. Org. Chem 2005, 70, 4980-4987. (f) Lm, I. H.; Kim, K. H.; Park, H. R.; Fujio, M.; Tsuno, Y. J. Org. Chem. 2004, 69, 3937-3942.

5. Lm, I. H.; Jeon, S. E.; Seok, J. A. Chem. E1m. J. 2006, 12, 1237 1243 .

6. (a) Umm, 1. H.; Park, Y. M.; Fujio, M.; Mishima, M.; Tsuno, Y. J. Org. Chem. 2007, 72, 4816-4821. (b) Lm, 1. H.; Akhtar, K.; Park, Y. M.; Khan, S. Bull. Korean Chem. Soc. 2007, 28, 1353-1357.

7. (a) Lm, I. H.; Min, J. S.; Lee, H. W. Con. J. Chem. 1999, 77, 659666. (b) Lm, I. H.; Kim, K. H.; Park, H. R.; Fujio, M.; Tsuno, Y. J. Org. Chen. 2004, 69,3937-3942.

8. (a) Techniques of Organic Chemistrr, $4^{\text {th }}$ ed.; Bemasconi, C. F., Ed.; Wiley: New York, 1986; vol. 6. (b) Techniques of Organic Chemistri, $3^{\text {th }}$ ed.; Lewis, E. S., Ed.; Wiley: New York, 1974; vol. 6, part 1. (c) Allences in Linear Free Energr Relationship; Chapman, N. B.; Shorter, I., Eds.; Plenum: London, 1972.

9. (a) Um, I. H.; Akhtar, K. Bthl. Korewn Chem. Soc. 2008, 29, 772776. (b) Lm, I. H.; Seo, J. A.; Chun, S. M. Bull. Korean Chem. Soc. 2008, 29, 1359-1363.

10. (a) Um, I. H.; Shin, Y. H.; Han, J. Y.; Mishima, M. J. Org. Chem. 2006, 71, 7715-7720. (b) Lm, I. H.; Akhtar, K.; Shin, Y. H.; Han, J. Y. J. Org. Chent 2007, 72, 3823-3829.

11. Bell, R. P. The Proton in Chemistr; Methuen: London, 1959; 159.

12. Castro, E. A.; Moodie, R. B. J. Chem. Soc., Chem. Commum. 1973, 828-829. 